\title{
Price of European journals
}

SIR - Over the past three or four years, we have become increasingly concerned because some European, particularly British, publishers charge higher prices to North American readers than to those in other parts of the world.

One may well ask why Nature costs $\$ 230$, or about $£ 160$, in the United States, whereas it costs only $£ 98$ in the United Kingdom and $£ 120$ in the rest of the world. The surprise and vexation of American librarians becomes greater when we have to pay $\$ 588$ ( $£ 405)$ for the Philosophical Magazine, which costs only $£ 207$ elsewhere.

We could expand this list. Unfortunately, the practice is spreading among both commercial and society publishers. But the two examples suffice to illustrate the problem. One shows a questionable but still modest surcharge of 30 per cent, the other a not unusual doubling of the price for US subscribers.

When asked to explain this practice, publishers tend to cite the cost of air freight and unstable exchange rates. But air despatch is neither limited to North America nor more costly than it is to other overseas countries. Nor can this cost justify the difference in prices. Foreign exchange rates have moved for several years in one general direction and have consistently benefited the foreign publisher who early sets his price in dollars, not to speak of the one who sets it at unrealistic levels. When, years ago, the dollar was steadily declining in relative value, the same publishers did not hesitate to issue supplementary invoices or to demand payment in their countries' currency. What seemed fair then, is fair now. If publishers demanded payment in pounds sterling then, they cannot in good faith demand it in dollars now.

The American representative of a major British university press recently let the cat out of the bag by noting that the higher prices were not based on exchange rates or shipping costs but were the result of the opportunities presented by "different markets".

We find these practices unacceptable. They put a further library cost burden of perhaps several million dollars on researchers in the United States and only aggravate an already critical situation.

Apart from direct but futile correspondence with publishers and subscription agents, we have brought our objections to the attention of the American Library Association, the Special Libraries Association and the Association of Research Libraries. One of us is preparing a paper on the topic for publication in a US library journal, in which he intends to use and expand on the material in this letter.

We have cancelled some British journals and have not subscribed to some new ones because of higher prices for US libraries.
For some journals from other European countries we have been able to take other measures, and we are exploring the possibility of similar arrangements in England.

Linda Hall Library,

LARRY X. BESANT

SIEGFRIED RUSCHIN

5109 Cherry Street,

Kansas City, Missouri 64110, USA

- Until October 1975, the price of Nature in the UK was $£ 27.50$, while US subscribers were supplied by surface mail (at $£ 31$ a year) or by airmail ( $£ 50$ a year). Later in 1975 , in October, arrangements were made to supply US subscribers by air-speed delivery and the price of Nature was fixed at $\$ 35$ in the United Kingdom and \$95 in the United States. I am sure that with the dollar converting at more than two to the pound and with the extra cost of air-speed, the prices were virtually identical. Since the end of 1975, the price of Nature has increased from $£ 35$ to $£ 98$, a ratio of 2.7 , while the price of a full subscription in the United States has been increased to $\$ 230$, a ratio of 2.4. Since November 1982, the price of Nature in both countries has remained essentially unchanged, and will not change until at least the end of 1985 . But unhappily, with the rapid decline of sterling relative to the dollar, the US price seems relatively much greater than that in the United Kingdom. But it is worth also saying that since we now manufacture American copies in the United States and are thereby (we hope) able to provide an even faster service than air-speed allows, we have to pay substantial printing bills in the United States and are thus less able to profit from the dollar's strength. Editor, Nature.

\section{Tropical malaise}

SIR - The current decline in tropical ecology pointed out by Norman Cole (Nature 309, 204; 1984) is one for which there is no immediate prospect of reversal. The problem is one of the availability of appropriately trained manpower and extends into applied areas such as agriculture and fisheries. There is a significant demand for people of this type from developing countries in the tropics by the international agencies and overseas universities but the rate of replacement appears much slower. Often the most promising individuals in a government department of a developing country disappear abroad, understandably to take up more rewarding appointments in these situations, with no qualified junior who might profit from the increased experience to take over. There appears, therefore, to be a net loss of people at the highest level which exceeds the current availability of trained experienced people.

In the developed countries it is not just that economic stringency has led to a reduction in the number of projects in the tropics but, more to the point, the number of opportunities for recent graduates to gain tropical experience is becoming severely limited. This is particularly noticeable in a country such as Britain which has a substantial tradition of work in tropical biology; however, the number of outlets for younger scientists to gain the crucial initial experience are now very few, and are principally through the voluntary agencies, with a few through government technical assistance programmes. This can only lead within the next decade or so to a much reduced commitment by this country to the tropical sciences. A few countries, such as Norway and the Netherlands, are increasing the opportunities for their scientists, including those newly qualified, to work in the tropics, which will provide a cadre of experienced workers in the medium term, although the total numbers may not be so great.

All of these factors add up to a rather discouraging prospect. The sparse distribution of experienced scientists from the developing countries and the international drain on these resources in conjunction with the progressive limits on the possibilities for young scientists from the developed countries to gain the all-important first experience in the tropics could well precipitate a manpower crisis in ecology and food production sciences in ten to fifteen years' time.

Department of Biological Sciences,

Coventry (Lanchester) Polytechnic, Coventry CVI SFB, UK

\section{Sea of subdued light}

SIR - I wonder whether there is any interest in Ruskin's account of Homer's sea?

Ruskin says ':

As far as I can trace the colour perception of the Greeks, I find it all founded primarily on the degree of connection between colour and light; the most important fact to them in the colour of red being its connection with fire and sunshine; so that "purple" is, in its original sense, "fire-colour", and the scarlet, or orange, of dawn, more than any other fire colour. I was long puzzled by Homer's calling the sea purple; and misled into thinking he meant the colour of cloud shadows on green sea; whereas he really means the gleaming blaze of the waves under wide (sic) light. Aristotle's idea (partly true) is that light, subdued by blackness, becomes red; and blackness, heated or lighted, also becomes red. Thus, a colour may be called purple because it is light subdued (and so death is called "purple" or "shadowy" death); or else it may be called purple as being shade kindled with fire, and thus said of the lighted sea; . . .

J. BENTLEY

179 Howlands

Welwyn Garden City,

Herts AL7 4RL, UK

1 Ruskin, J. The Queen of the Air: Being a Study of the Greek Myths of Cloud and Storm, 110-111 (George Allen, Orpington, 1869) 